\title{
Evolution of Quality Improvement for the Journal of Ko- rean Neurosurgical Society
}

\author{
Bum-Tae Kim, M.D., ${ }^{1}$ Moonyoung Chung, M.D. ${ }^{2}$ \\ Editor-in-Chief,' Journal of Korean Neurosurgical Society; Department of Neurosurgery, Soonchunhyang University Bucheon Hospital, \\ Bucheon, Korea \\ Editorial Staff, ${ }^{2}$ Journal of Korean Neurosurgical Society; Department of Neurosurgery, Soonchunhyang University Bucheon Hospital, \\ Bucheon, Korea
}

The Korean Neurosurgical Society (KNS) was established in 1961 and first published the Journal of Korean Neurosurgical Society (JKNS) on October 31, 1972 $2^{4}$. Since then, all papers have been published in English since July 2005, and the journal was listed in Excerpta Medica database (EMBASE) in 2005 and PubMed in 2007. It has become internationally recognized after being listed in Scientific Citation Index Expanded (SCIE) in $2008^{1}$. However, following that listing, the growth trend slowed down. There were many problems that contributed this situation which are difficult to overcome. Lack of awareness of publishing ethics decreased the scientific quality of our journal. The domestic nature of our journal has made it difficult for world researchers to submit their works. And these problems resulted in stagnation of the impact factor ${ }^{3)}$. In the end, it was necessary to review the problem and develop solutions to it, and the role of the editorial committee became important. As a result, a member of KNS has been awarded the honor of being the author of the most cited articles in JKNS. It seemed that this effort was the most practical way to give our neurosurgical society members experience to contribute to improving the impact factor on a short-term basis. The crosscheck system was introduced in December 2014 to follow worldwide trend for a higher ethical quality. We have also encouraged review articles since 2014, and reinforced rules for the submission and reviewing case reports from $\mathrm{Au}-$ gust 2015. In January of 2016, the journal changed from a monthly issue to a bi-monthly issue. As a result of these efforts, the impact factor of JKNS in 2017 was 0.860 , the highest score than that of the past years (Fig. 1). In July of 2017, the manuscript submission system was reorganized on the new homepage. Despite these efforts, the status of JKNS has not been as influential as the other international journals ${ }^{2}$. Therefore, I would like to try to improve the quality of JKNS by evolving the journal as the new Eitor-in-Chief.

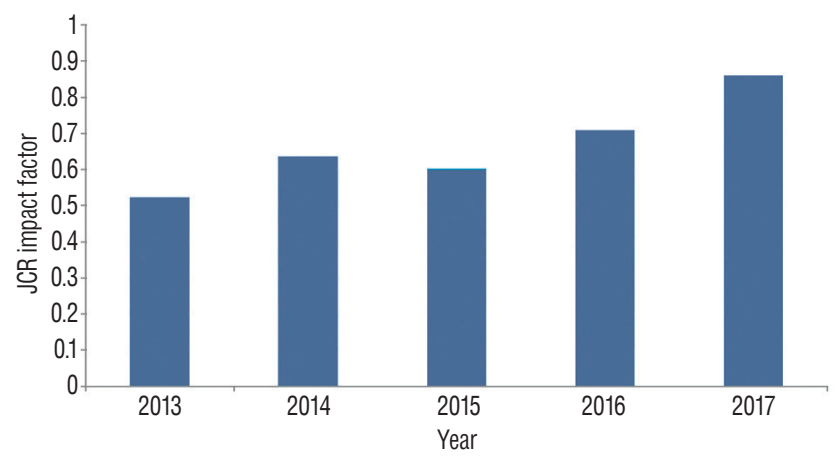

Fig. 1. This graph shows an increasing trend of the impact factor of the InCite Journal Citation Reports (JCR), which was 0.860 in 2017.

- Received : April 22, 2018 •Revised : May 15, 2018 •Accepted : June 27, 2018

-Address for reprints : Bum-Tae Kim, M.D.

Department of Neurosurgery, Soonchunhyang University Bucheon Hospital, 170 Jomaru-ro, Wonmi-gu, Bucheon 14584, Korea Tel : +82-32-621-5059, Fax : +82-32-621-5016, E-mail : bumtkim@schmc.ac.kr

This is an Open Access article distributed under the terms of the Creative Commons Attribution Non-Commercial License (http://creativecommons.org/licenses/by-nc/4.0) which permits unrestricted non-commercial use, distribution, and reproduction in any medium, provided the original work is properly cited. 
First, such evolution further strengthened the ethics of publishing. As recent ethical issues have been emphasized, studies handling human subjects, especially prospective interventional studies, have to be obtained informed consent from patients, and related statement should be addressed in the manuscripts. Retrospective studies have also mandated that the outcome of reviews of each institution by an institutional review board should be clearly stated in the paper. Redundant publication, plagiarism, and data fabrication are strongly prohibited, and the authors should clearly state that there is no conflicts of interest between researchers or research institutions in the manuscript. Regarding authorship, we have banned unreliable authors such as ghost authors and gift authors, and have explicitly indicate the roles of the first authors and the correspondent authors. Second, at the time a new article is published, a letter introducing the publication of a new and interesting subject is sent to the all members of KNS and all contributors who have submitted to JKNS. Third, we send congratulatory messages to authors of JKNS citation paper, and quote the citations from the articles. Fourth, e-publication is underway for the papers being published after acceptance. Fifth, the review articles will be requested to the invited speakers of the KNS annual conferences, and articles will be compulsorily obligated to the project managers of the Policy Research Project of the KNS and the speakers of plenary session of KNS annual conferences. Finally, we will deeply consider recruiting new peer reviewers. We issue a newsletter to inform editors and peer reviewers about the status/statistics of submitted manuscripts, their acceptance rate, and the duration of the review process for each editor. Also, we will announce the best JKNS reviewer every year.

For the ultimate quality improvement of JKNS, it is necessary to make constant efforts to publish the journal to increase influence together with article authors, reviewers, and editors. Members of KNS are encouraged to submit a good study result to JKNS first. The editors should select peer reviewers who can most logically review the manuscripts sub- mitted by national or international authors and exchange the opinions with them in order to complete the review in the shortest time. Peer reviewers who have expertise and participate in the review should review the submitted manuscripts in a positive way and send the contents of the review to the editors within the mandatory period. These diverse efforts will be the cornerstone of JKNS evolution into a scientific journal with an even greater international influence. Surely, we will play a role in the administrative and academic aspects of the evolution of the quality improvement of JKNS.

\section{CONFLICTS OF INTEREST}

No potential conflict of interest relevant to this article was reported.

\section{INFORMED CONSENT}

This type of study does not require informed consent.

\section{- Acknowledgements}

This work was supported by the Korean Neurosurgical Society and the Soonchunhyang University Research Fund.

\section{References}

1. Cheong JH, Kim JM, Bak KH, Kim CH : Correlation between cerebral vasospasm after subarachnoid hemorrhage and intercellular adhesion molecule-1 levels in serum and cerebrospinal fluid. J Korean Neurosurg Soc 38 : 1-11, 2005

2. Dacey RG Jr : Obituary: John Anthony Jane Sr., MD, PhD, 1931-2015. J Neurosurg 2016 : 1-4, 2016

3. Jane JA Sr : Editorial: maintaining journal independence. J Neurosurg $118: 919,2013$

4. Lee CK : Surgical treatment of epilepsy: preoccipital coagulation. J Korean Neurosurg Soc 1 : 1-14, 1972 